\title{
Umbilical Artery Doppler Waveform Indices at Term
}

\author{
${ }^{1}$ Muhammad Yousaf, ${ }^{2}$ Syeda Khadija, ${ }^{3}$ Raham Bacha, ${ }^{4} \mathrm{M}$ Athar A Shams, ${ }^{5}$ Syed Zain-ul-abidin
}

\begin{abstract}
Aim: This study was designed to evaluate umbilical artery Doppler indices [systolic/diastolic (S/D) ratio and pulsatility index $(\mathrm{PI})]$ in normal fetus at term. Doppler ultrasound of umbilical arteries is widely accepted as a primary tool for quantitative analysis of fetoplacental and uteroplacental blood flow in highrisk pregnancies.
\end{abstract}

Materials and methods: A total of 100 normal singleton pregnant women were recruited in this study from the Radiology Department Fatima Memorial Hospital (FMH) from August 3, 2012 to November 30, 2012. Their gestational ages were from 37 to 40 weeks.

Results: A total of 100 Doppler indices measurements were performed. The values of S/D ratio were less than 3 and the values of mean PI were less than 1 from 37 to 40 weeks of gestation.

Conclusion: Umbilical artery Doppler indices among normal pregnant women in our population are similar to most published reference values from other parts of the world.

Clinical significance: This normative data will serve as a basis for the evaluation of the umbilical artery circulation in our population.

Keywords: Doppler indices (systolic/diastolic ratio, pulsatility index), Term, Umbilical artery.

How to cite this article: Yousaf M, Khadija $S$, Bacha $R$, Shams MAA, Zain-ul-abidin S. Umbilical Artery Doppler Waveform Indices at Term. Donald School J Ultrasound Obstet Gynecol 2018;12(2):104-107.

Source of support: Nil

Conflict of interest: None

\section{INTRODUCTION}

Adequate quantity of blood (nutrients and oxygen) is required for the proper growth of the fetus during pregnancy. ${ }^{1}$ The main blood supply to the uteroplacental and fetoplacental circulation is from uterine and umbilical arteries. $^{2}$ As normal pregnancies advance, blood flow in the umbilical arteries increases with the consequent decrease in placental resistance, characterized by good

\footnotetext{
${ }^{1}$ Lecturer, ${ }^{2,3}$ Senior Lecturer, ${ }^{4,5}$ Demonstrator

${ }^{1-5}$ Department of Radiological Sciences and Medical Imaging Technology, Faculty of Allied Health Sciences, University of Lahore, Lahore, Pakistan

Corresponding Author: Muhammad Yousaf, The University of Lahore, 1 - KM Defence Road, Lahore, Pakistan, Phone: +923214694881, e-mail: yousaf_mit@yahoo.com
}

diastolic flow and fall in Doppler indices. Figure 1 show umbilical artery normal Doppler indices from 37 to 40 weeks respectively.

In certain pathologic conditions that lead to uteroplacental insufficiency, blood flow in the umbilical arteries is reduced. This is characterized by absent or reversed diastolic flow and increased Doppler indices. ${ }^{3}$ It is reported consistently by several studies that risk for adverse pregnancy outcomes including preeclampsia and intrauterine growth retardation (IUGR) is high in women who fail to establish a low-resistance uteroplacental circulation. ${ }^{4}$ In response to progressive hypoxemia, the fetus may redistribute its blood supply centrally to brain, heart, and adrenals. This results in increased diastolic flow in middle cerebral artery. ${ }^{5}$

Doppler has been widely accepted as the primary tool for surveillance of pregnancies affected from preeclampsia and IUGR secondary to placental insufficiency. ${ }^{6-9}$

In cases of suspected IUGR, several fetal vessels can be investigated but the society for maternal-fetal medicine guidelines recommends umbilical artery Doppler as an initial tool for interrogation. ${ }^{10}$ Doppler should be used as a screening tool in the 2nd half of pregnancy, as it detects abnormal vascular resistance patterns in the umbilical arteries noninvasively ${ }^{11}$ and safely. ${ }^{12}$ It will help to reduce the number of antenatal examinations and cesarean deliveries for suspected fetal distress in high-risk pregnancies. ${ }^{13}$

Doppler indices [S/D ratio, PI, resistance index (RI)] are mathematical formulas that attempt to estimate the relative difference in flow velocity between systole and diastole. ${ }^{14}$ Peak S/D ratio and PI are most commonly used Doppler indices for assessment of umbilical arteries. ${ }^{15}$

Doppler velocimetry has improved our understanding of pathophysiological processes leading to IUGR and possibilities of monitoring fetal health. It is an excellent method to differentiate between healthy and growthretarded fetuses and may help to identify pregnancies that need special fetal surveillance. ${ }^{11}$

\section{MATERIALS AND METHODS}

In this study, nonprobability, consecutive sampling was performed to obtain normal reference values of umbilical artery in the third trimester of pregnancy among healthy normotensive pregnant women. Research was started after approval from institutional review board. 


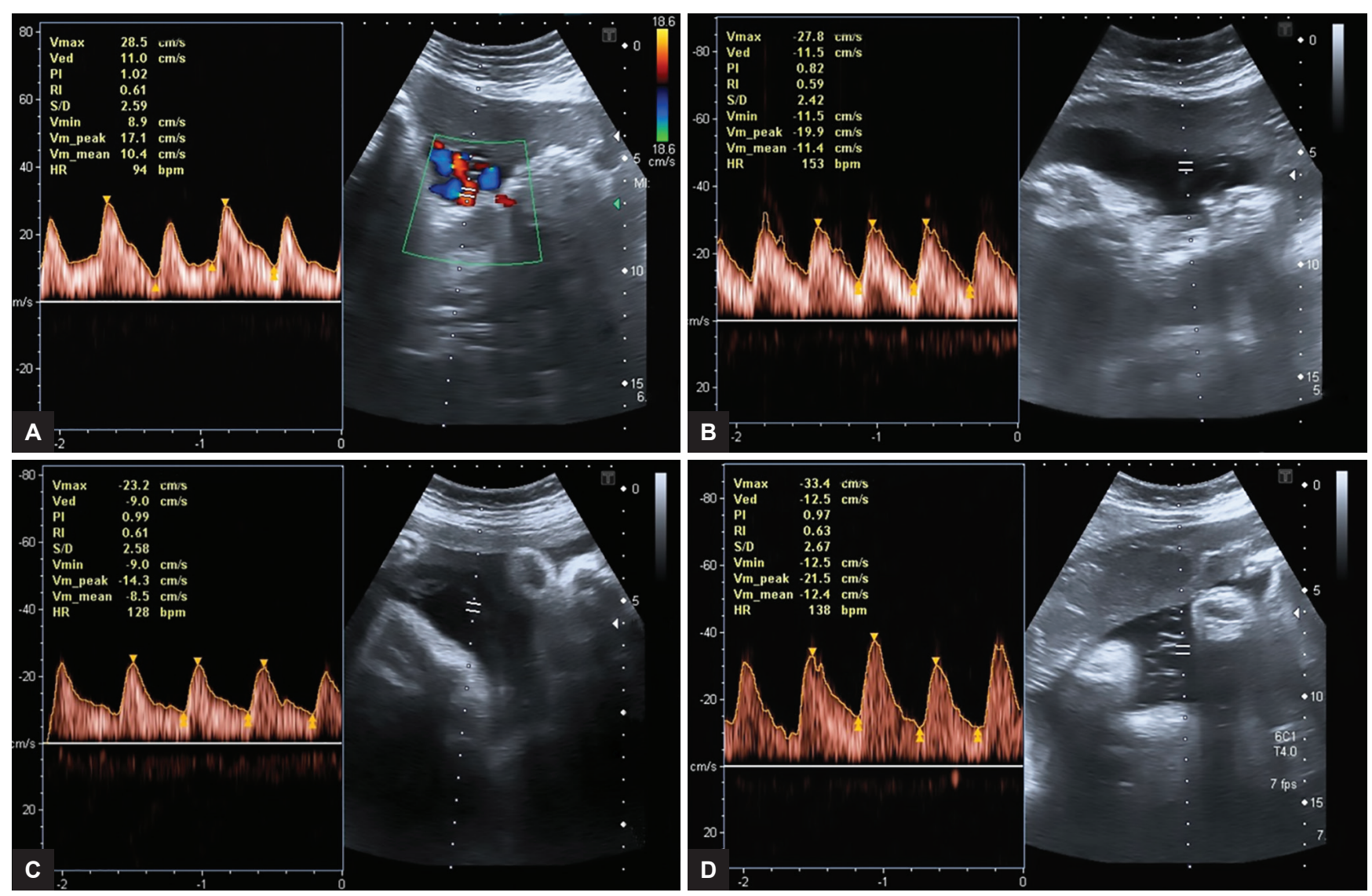

Figs 1A to D: Umbilical artery normal Doppler waveform indices at (A) 37 weeks (S/D 2.59, PI 1.02), (B) 38 weeks (S/D 2.42, PI 0.82), (C) 39 weeks (S/D 2.58, PI 0.99), (D) 40 weeks (S/D 2.67, PI 0.97)

Sample size was determined with post hoc sampling techniques. The study was conducted at the Radiology Department, FMH, Shadman, Lahore, from August 3, 2012 to November 30, 2012. Both indoor and outdoor patients were included in this study.

All pregnant women were examined by GE 730 pro Volsun and Toshiba Xario Doppler ultrasound machine using the convex probe. Before examination, procedures were explained to each patient and informed consent was obtained. The abdominal and pelvic area was exposed, transmitting gel was applied. The transducer was placed over the parauterine area and the umbilical cord was located by real-time gray-scale ultrasound and color Doppler. Then pulsed Doppler was utilized with optimum settings to avoid aliasing or very small spectrum. The sample volume was selected at approximately mid cord level in one of the umbilical arteries and searched until characteristic waveforms were obtained. Waveforms were obtained three times per patient and the Doppler indices were calculated from the optimum one.

Pregnant women with singleton pregnancy at 37 to 40 weeks of gestational age, with certain last menstrual period were recruited. All the fetuses having a difference of less than 3 standard deviation in their biometric parameters were included. Pregnancies with uterine, placental, and fetal anomalies were excluded.

Collected information was entered to Statistical Package for the Social Sciences computer software program and analyzed accordingly. The mean and standard deviation of the umbilical artery Doppler indices were derived for descriptive analysis.

There was no ethical issue, as it was an observational study.

\section{RESULTS}

In this study, a total of 100 subjects were recruited and Doppler indices measurements were performed. The ranges of S/D and PI from 37 to 40 weeks of gestation are shown in Table 1. Mean values with the standard deviation of S/D and PI from 37 to 40 weeks of gestation

Table 1: Range of Doppler indices

\begin{tabular}{|c|c|c|c|c|c|}
\hline \multirow[b]{2}{*}{ Weeks } & \multirow[b]{2}{*}{$n$} & \multicolumn{2}{|c|}{$S / D$} & \multicolumn{2}{|c|}{$P I$} \\
\hline & & Minimum & $\overline{\text { Maximum }}$ & Minimum & Maximum \\
\hline 37 & 25 & 1.68 & 2.90 & 0.52 & 1.00 \\
\hline 38 & 25 & 1.66 & 2.80 & 0.64 & 1.10 \\
\hline 39 & 25 & 1.61 & 2.96 & 0.50 & 1.11 \\
\hline 40 & 25 & 1.60 & 2.80 & 0.46 & 1.04 \\
\hline
\end{tabular}


Table 2: Doppler indices and standard deviation

\begin{tabular}{lllllll}
\hline & & \multicolumn{2}{c}{$S / D$} & & \multicolumn{2}{c}{ Pl } \\
\cline { 7 - 7 } \cline { 6 - 7 } Weeks & $n$ & Mean & $\begin{array}{l}\text { Standard } \\
\text { deviation }\end{array}$ & & Mean & $\begin{array}{l}\text { Standard } \\
\text { deviation }\end{array}$ \\
\hline 37 & 25 & 2.2830 & 0.32147 & & 0.7999 & 0.13415 \\
38 & 25 & 2.1968 & 0.27010 & & 0.8040 & 0.11655 \\
39 & 25 & 2.3284 & 0.41829 & & 0.8232 & 0.18057 \\
40 & 25 & 2.2180 & 0.35253 & & 0.7680 & 0.15843 \\
\hline
\end{tabular}

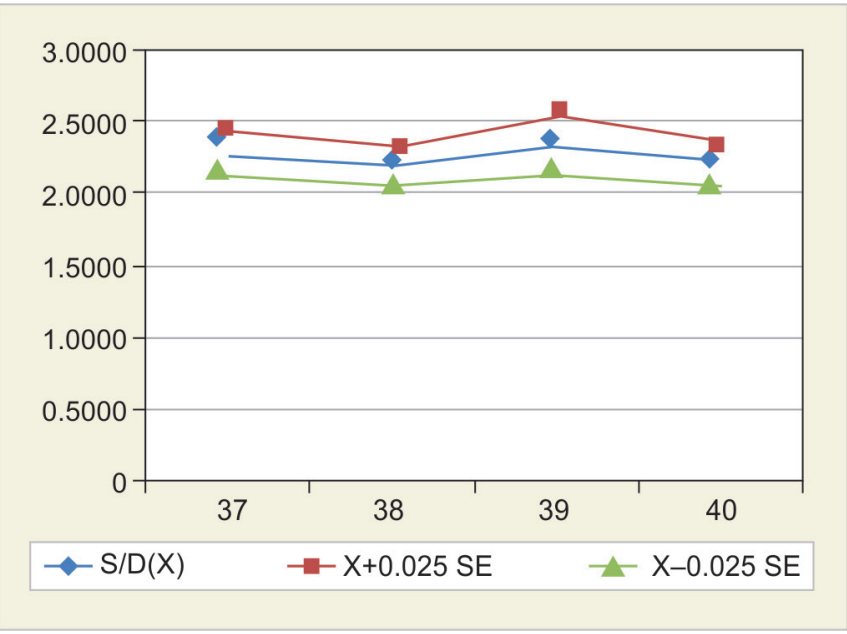

Graph 1: $95 \% \mathrm{Cl}$ for S/D

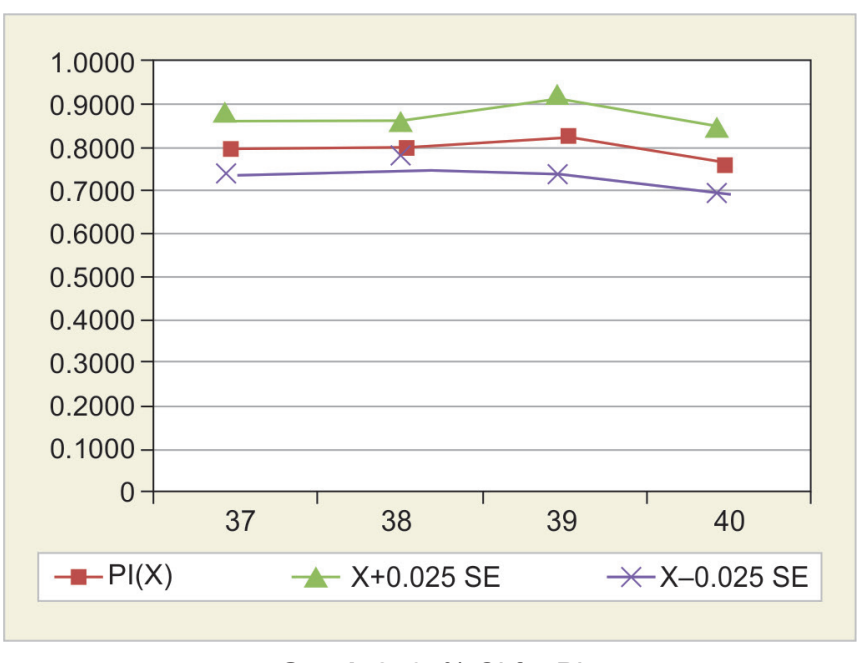

Graph 2: $95 \% \mathrm{Cl}$ for $\mathrm{PI}$

are shown in Table 2. Graph 1 shows 95\% confidence interval (CI) for S/D ratio from 37 to 40 weeks of gestation. Graph 2 shows 95\% CI for PI from 37 to 40 weeks of gestation.

\section{DISCUSSION}

Doppler ultrasound is an established, noninvasive, easily accessible, and cheap method for assessment of fetoplacental circulation ${ }^{16}$ and is an accurate method for diagnosis and management of fetal growth retardation. ${ }^{17}$ Doppler velocimetry of umbilical arteries reflects the development of the placental villous vasculature and is a reliable tool in the diagnosis and conservative management of fetal growth restriction before term. ${ }^{18}$

The slight variations in values of Doppler indices may occur due to several factors like gestational age, fetal heart rate, fetal breathing, site of measurement in the cord, race, inter- and intraobserver measurement variations that have been reported to affect Doppler indices. ${ }^{19}$

Gupta et $\mathrm{al}^{20}$ in India found high values of umbilical artery Doppler indices in hypertensive group than in the normotensive group of the same gestation. Saeed et $\mathrm{al}^{11}$ in Pakistan concluded that their results of Doppler indices in umbilical artery vary as compared with international data. In their study, mean S/D, PI, and RI were 4.68, 1.48, and 0.78 respectively, at 22 weeks of gestation.

In our study, the mean values of umbilical artery Doppler indices (S/D, PI) are similar to the study reported by Chanprapaph et al ${ }^{19}$ and Owen et al. ${ }^{21}$ The values of mean PI are similar to those reported by Acharya et $\mathrm{al}^{22}$ in Norway and Ferdous et $\mathrm{al}^{23}$ in Bangladesh. The values of mean S/D are similar to those reported by Kofinas et $\mathrm{al}^{24}$ in North Carolina, Harneet et $\mathrm{al}_{,}{ }^{25}$ and Singh ${ }^{26}$ in India.

In this study, we have documented the normal values and mean values of umbilical artery Doppler indices (S/D ratio, PI) in normal singleton pregnant women in Pakistani population. It is believed that the data presented here can represent our normal population and be used as baseline data in the evaluation of fetal umbilical arteries resistance due to adequate sample size and well-selected patients with normal pregnancies.

\section{CONCLUSION}

Umbilical artery Doppler indices among normal pregnant women in our population are similar to published reference values from other parts of the world.

\section{CLINICAL SIGNIFICANCE}

This normative data will serve as a basis for the evaluation of the umbilical artery circulation in our population.

\section{RECOMMENDATIONS}

It is recommended to reduce the influence of several factors affecting Doppler indices: The reference range of umbilical artery Doppler indices should be derived from the local population. Further studies should be done with a larger sample size including multiple classes of gestational age from second trimester to term.

\section{REFERENCES}

1. Jacobson SL, Imhof R, Manning N, Mannion V. The value of Doppler assessment of uteroplacental circulation in predicting preeclampsia and intrauterine growth retardation. Am J Obstet Gynecol 1990 Jan;162(1):110-114. 
2. Rochelson BL, Schulman H, Fleischer A. The clinical significance of Doppler umbilical artery velocimetry in small for gestational age fetuses. Am J Obstet Gynecol 1987 May;156(5): 1223-1226.

3. Lakhkar BN, Ahamed SA. Doppler velocimetry of uterine and umbilical arteries during pregnancy. Indian J Radiol Imaging 1999;9(3):119-125.

4. Papageorghiou AT, Yu CK, Bindra R, Pandis G, Nicolaides KH; Fetal Medicine Foundation Second Trimester Screening Group. Multicenter screening for preeclampsia and fetal growth restriction by transvaginal uterine artery Doppler at 23 weeks of gestation. Ultrasound Obstet Gynecol 2001 Nov;18(5):441-449.

5. Ferrazzi E, Bozzo M, Rigano S, Bellotti M, Morabito A, Pardi G, Battaglia FC, Galan HL. Temporal sequence of abnormal Doppler changes in the peripheral and central circulatory systems of the severely growth-restricted fetus. Ultrasound Obstet Gynecol 2002 Feb;19(2):140-146.

6. Alfirevic Z, Stampalija T, Gyte GM. Fetal and umbilical Doppler ultrasound in high-risk pregnancies. Cochrane Database Syst Rev 2010 Jan;(1):CD007529.

7. Royal College of Obstetricians and Gynaecologists (RCOG). Green-top guideline. The investigation and management of the small-for gestational-age fetus. London: RCOG Press; 2002.

8. Maulik D, Mundy M, Heitmann E. Evidence-based approach to umbilical artery Doppler fetal surveillance in high-risk pregnancies: an update. Clinical Obstet Gynecol 2010 Dec;53(4):869-878.

9. American College of Obstetricians and Gynecologists. Intrauterine growth restriction. ACOG practice bulletin no. 12 Washington, DC: American College of Obstetricians and Gynecologists; 2000.

10. Society for Maternal-Fetal Medicine Publications Committee, Berkley E, Chauhan SP, Abuhamad A. Doppler assessment of the fetus with intrauterine growth restriction. Am J Obstet Gynecol 2012 Apr;206(4):300-308.

11. Saeed M, Qureshi I, Tarin A, Ghani N, Hyder R, Rashid I. Doppler indices in fetoplacental and uteroplacental circulation at 22 weeks of gestation. Pak Armed Forces Med J 2006 Mar;56(1):7-11

12. Pepe P, Motta L, Pennisi M, Aragona F. Functional evaluation of the urinary tract by colour Doppler ultra sonography (CDU) in 100 patients with renal colic. Eur J Radiol 2005 Jan;53(1):131-135.

13. Ertan AK, Tossounidis HL, Schmidth W. Normal fetomaternal Doppler indices in the second and third trimester of pregnancy. In: Schmidth W, Kurjak A, editors. Colour Doppler sonography in gynecology and obstetrics. New York: Thieme; 2005. pp. 129-133.

14. Sanders R, Hall-Terracciano B. Clinical sonography: a practical guide, 5th edition. Wolters Kluwer 2016. p. 53.

15. Stuart B, Drumm J, FitzGerald DE, Duignan NM. Fetal blood velocity waveforms in normal pregnancy. Br J Obstet Gynaecol 1980 Sep;87(9):780-785.

16. Montague I, Dubbins PA. Clinical applications of Doppler ultrasound in obstetrics. In: Allan P, Dubbins PA, Norman McDicken W, Pozniak MA, editors. Clinical Doppler Ultrasound. 2nd edition. Philadelphia, PA: Churchill Livingstone Elsevier; 2006. p. 315.

17. Rana MJ, Amanuallah A, Farooq O. The role of umbilical artery Doppler indices in detection and management of feta 1 growth retardation. Biomedica 2005 Jan-Jun;21:4-7.

18. Todros T, Piccoli E, Rolfo A, Cardaropoli S, Guiot C, Gaglioti P, Oberto M, Vasario E, Caniggia I. Review: feto-placenta 1 vascularization: a multifaceted approach. Placenta 2011 Mar;32(Suppl 2):S165-S169.

19. Chanprapaph P, Wanapitak C, Tongsong T. Umbilical artery Doppler waveform indices in normal pregnancies. Thai J Obstet Gynaecol 2000 Jun;12:103-107.

20. Gupta U, Qureshi A, Samal S. Doppler velocimetry in normal and hypertensive pregnancy. Internet J Gynecol Obstet 2009;11(2):P1528-8439.

21. Owen P, Murphy J, Farrell T. Is there a relationship between estimated fetal weight and umbilical artery Doppler impedance indices?. Ultrasound Obstet Gynecol 2003 Aug;22(2):157-159.

22. Acharya G, Wilsgaard T, Berntsen GK, Maltau JM, Kiserud T. Reference ranges for serial measurements of blood velocity and pulsatility index at the intra-abdominal portion, and fetal and placental ends of the umbilical artery. Ultrasound Obstet Gynecol 2005 Aug;26(2):162-169.

23. Ferdous MA, Sharif MM, Mohiuddin AS, Shegufta F. Normal value of pulsatility index of umbilical artery in second and third trimester of pregnancy. Bangladesh Med Res Counc Bull 2013 Jul;39(1):42-44.

24. Kofinas AD, Espeland MA, Penry M, Swain M, Hatjis CG. Uteroplacental Doppler flow velocity waveform indices in normal pregnancy: a statistical exercise and the development of appropriate reference values. Am J Perinatol 1992 Mar;9(02):94-101.

25. Harneet N, Kapila AK, Kaur MM. Cerebral and umbilical arterial blood flow velocity in normal and growth retarded pregnancy. J Obstet Gynecol India 2009 Jan-Feb;59(1):47-52.

26. Singh SK. Study of systolic/diastolic ratios of the umbilical artery flow velocity waveforms in pregnant women. Indian Med Gazette 2014 Mar;148(3):93-96. 